\title{
Procedimiento de análisis para el estudio del proceso constructivo documentado del Colegio de Corpus Christi de Valencia
}

\author{
An analytical procedure for the study of the documented construction \\ process of the Seminary-School of "Corpus Christi" in Valencia (Spain)

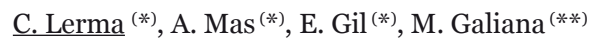

\section{RESUMEN}

El procedimiento de análisis de la secuencia constructiva de un edificio histórico debe establecer la relación entre el estudio de la documentación que se conserva y el estado actual del mismo, advirtiendo las incongruencias que se produzcan. Este trabajo se centra en el Colegio-Seminario de Corpus Christi de Valencia, que cuenta con una antigüedad de 400 años y conserva abundante documentación original relativa a su construcción. Se analizan con detalle todos los aspectos relacionados con la arquitectura y la construcción del edificio, aclarando cómo se produjo el proceso de construcción, facilitando un estudio gráfico de los gastos y una hipótesis tridimensional de la secuencia constructiva. La metodología que se propone puede servir para el estudio de procesos constructivos en otros edificios históricos.

Palabras clave: Arquitectura; patrimonio; construcción; Valencia; proceso constructivo.

\section{SUMMARY}

The analysis procedure of the historic building construction sequence must establish the relationship between the documentation study that is conserved and its current state, noting the inconsistencies that occur. This paper focuses on the Seminary-School of Corpus Christi of Valencia, which is 400 years old and retains plenty of original documents relating to its construction. All aspects of the architecture and the construction of the building are analyzed in detail. A graphic study of the costs and three-dimensional hypothesis of the building construction sequence clarify how occurred its construction process. The proposed methodology can be used to study other construction processes in historical buildings.

Keywords: Architecture; heritage; construction; Valencia; construction process.

(*) Universitat Politècnica de València, España.

(**) Universidad Católica S. Antonio de Murcia, España.

Persona de contacto/Corresponding author: clerma@csa.upv.es (C. Lerma)

Cómo citar este artículo / Citation: Lerma, C., Mas, A., Gil, E., Galiana, M. (2014). Procedimiento de análisis para el estudio del proceso constructivo documentado del Colegio de Corpus Christi de Valencia. Informes de la Construcción, 66(533): eo07, http:// dx.doi.org/10.3989/ic.12.117.

Licencia / License: Salvo indicación contraria, todos los contenidos de la edición electrónica de Informes de la Construcción se distribuyen bajo una licencia de uso y distribución Creative Commons Reconocimiento no Comercial 3.o. España (cc-by-nc). 


\section{INTRODUCCIÓN}

El edificio que nos ocupa, el Colegio-Seminario de Corpus Christi de Valencia (España) (Figura 1), y su construcción no se pueden entender de manera aislada sino enmarcados en su contexto histórico, social, político, religioso...

En la ciudad de Valencia, una de las personas más representativas del Renacimiento fue su obispo y patriarca de Antioquía, Juan de Ribera, quien decidirá construir un Colegio-Seminario cerca de la Universidad de Valencia con el objetivo de formar hombres dedicados y consagrados a celebrar los oficios propios de la iglesia. Ribera estuvo influenciado por la publicación de Carlos Borromeo Instructionum Fabricae et Suppellectilis Ecclesiasticae, en 1577. En Valencia se desarrolló plenamente un Renacimiento arquitectónico y fue en consonancia con el resto de la península aunque con algunas diferencias (1). En esta época era habitual construir gran cantidad de edificios religiosos, de hecho, en estos años 70 se construyeron hasta dieciocho iglesias de diferentes congregaciones religiosas. Isidoro Aliaga (2) incrementará la uniformidad a nivel constructivo en el siglo XVII con su control eclesiástico sobre las fábricas religiosas uniformadas según las reglas de la Contrarreforma, que prosigue la realización del proyecto iniciado por su predecesor, Juan de Ribera.

Para proceder a la construcción del edificio fue necesario adquirir las casas y propiedades que se encontraban en la manzana donde hoy se sitúa el Colegio-Seminario. Dichas compras se prolongaron en el tiempo (entre 1580 y 1601), incluso después de iniciarse las obras en 1586. Se ha constatado que la secuencia de adquisición de estas casas influyó de manera decisiva en el proceso constructivo del edificio (3).

En el Archivo del Colegio de Corpus Christi se encuentra un libro llamado Libro de Construcción y Fábrica o Libro de los Gastos (4) que recoge los gastos que generó la construcción de este singular edificio, que comenzó en 1586 y finalizó en 1610. En este artículo explicamos cómo debe analizarse la documentación, las conclusiones que hemos extraído y su aplicación. Es interesante apuntar que la metodología del presente estudio se puede generalizar y aplicar a otros trabajos cuyos edificios sean de similares características, es decir, se trate de un edificio histórico y religioso donde se haya conservado parte de la documentación original.

Los alzados de las fachadas y el modelo $3 \mathrm{D}$ del edificio han sido generadas por los autores con la información proporcionada por el láser escáner. El edificio estudiado es de grandes dimensiones, geometría compleja y se encuentra situado entre calles estrechas, por lo que esta técnica es adecuada (5).

\section{MÉTODO}

En la Tabla 1 se muestran las fases que se han desarrollado en este trabajo. La primera se centra en los diferentes tipos de documentación que son de utilidad a la hora de determinar y clarificar el proceso constructivo de un edificio histórico. La segunda fase consiste en analizar dichos documentos centrándose en las partes más significativas del edificio.

\subsection{Documentación}

En el Archivo del Colegio del Patriarca se conserva el libro original donde se apuntaban los gastos derivados de la construcción del Colegio. A finales del siglo XIX se hizo una copia que es a la que hemos podido tener acceso. Dicho libro se titula Libro de Construcción y Fábrica y se redactó en el año 1892. Se trata de un libro de gran formato que consta de más de 800 páginas.

La estructura del libro intenta ser cronológica aunque hay partes en que se resumen todos los gastos pertenecientes a una partida específica; así, tenemos un memorial para el yeso, para ladrillo, jornales, reble, carreteros, cal, madera, así como unos resúmenes al final del libro.

La información que se recoge son los gastos, fechados y agrupados por meses y años según un orden cronológico no muy estricto. Se intenta citar al maestro que las cobraba y se sitúa el importe. Hemos realizado un vaciado de la información contenida en el libro y la hemos informatizado de tal forma que nos permita ordenar cronológicamente todas las parti-

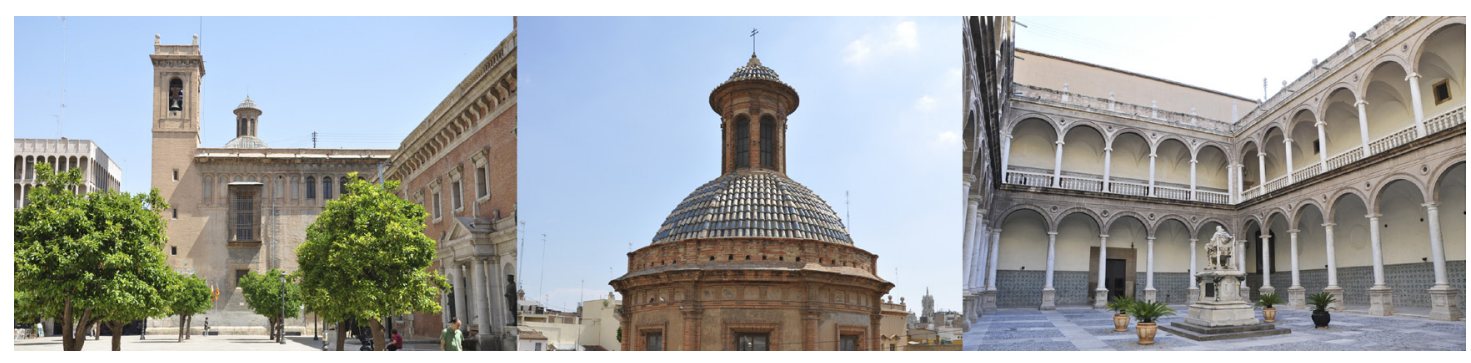

Figura 1. Vista general del Colegio de Corpus Christi.

Tabla 1.

Resumen de la metodología llevada a cabo.

\begin{tabular}{|c|c|c|c|c|l|}
\hline AÑO & MES & DÍA & MATERIAL & LIBRAS & \multicolumn{1}{|c|}{ OBSERVACIONES } \\
\hline 1586 & 10 & 11 & Jornales & 14,40 & Piedra. Maestro Damian \\
\hline 1586 & 10 & 30 & Piedra & 0,00 & Primera piedra \\
\hline 1586 & 10 & 31 & Jornales & 21,60 & Cédula y jornales. Maestro Lloret \\
\hline 1586 & 10 & 31 & Cal & 6,40 & Cédula de piedra hita cal a Jeronimo \\
\hline 1586 & 10 & 31 & Yeso & 4,50 & Cédula de piedra de este día por yeso al maestro Joaquin Jillol \\
\hline 1587 & 1 & 10 & Arena & 3,85 & A Juan Sarcia arenero \\
\hline 1587 & 1 & 3 & Madera & 8,70 & A Vicente Sanchez carpintero \\
\hline
\end{tabular}


das, sumar las cantidades y filtrar resultados con el objetivo de conseguir resultados escritos o gráficos que nos ayuden en el desarrollo de nuestro trabajo.

Hemos introducido la información de todos aquellos gastos que se han considerado de interés para el presente trabajo, descartando partidas que no tienen que ver con la construcción del Colegio. En total son 9616 ítems entre los años 1586 y 1610 cuyo valor asciende a 165500,70 libras.

A modo de ejemplo, en la Tabla 2 se muestran los primeros gastos ordenados cronológicamente.

La Figura 2 resume lo más detalladamente posible todos los gastos en la construcción del Colegio documentados por el Libro de Gastos y se muestran los gastos con periodicidad mensual.

Con esta figura nos podemos hacer una buena idea de cómo se produjo el proceso de construcción del Colegio. Desde el inicio de la obra en octubre de 1586 los gastos se han ido incrementando hasta el año 1604, a partir del cual se produjo un descenso considerable.

Como puede apreciarse, hemos subdividido la gráfica en cuatro fases en función de la importancia de los gastos que se producen.

- Primera Etapa: Abarca desde el inicio de la obra hasta octubre de 1590, pues en noviembre se firma el contrato con el maestro Guillem del Rey. El gasto medio mensual se sitúa en el $0,11 \%$. En este período se procede a la construcción de la cimentación de los muros perimetrales del edificio, salvo algún tramo concreto cuyo terreno aún no había sido adquirido por el Patriarca Ribera.

- Segunda Etapa: Comprende desde noviembre de 1590 hasta mayo de 1596. El gasto medio mensual aumenta ligeramente hasta el $0,15 \%$. Excepto un breve paréntesis, en este tramo se desarrollará la Iglesia, el enlosado y las gradas. Además, se completará la fachada recayente a la calle de la Nave (1593-1595) y en 1595 comenzará a ejecutarse el cimborrio. Cabe destacar que a finales de este período el rey Felipe III acepta el patronazgo de la obra y Francisco de Sandoval y Rojas, duque de Lerma, comenzaba su virreinato.

- Tercera Etapa: la más dilatada en el tiempo y la que tiene un mayor índice de gasto medio mensual (0,63\%). Abarca desde junio de 1596 (en que se incrementa el gasto respecto del mes anterior en un 330\%) hasta noviembre de 1605 (en que cae el gasto en un 250\%). Comprende la construcción de la mayoría de los elementos del Colegio: finalización de la iglesia, de la cúpula, se colocan azulejos en los muros, se construyen escaleras, el pintor Bartolomé Matarana se encarga de las vidrieras y de las pinturas, el campanario, el claustro (columnas, bóvedas y azulejos), además de realizar la mayor parte del mobiliario y de los relicarios. Los monarcas no se olvidan de esta obra emblemática y cuando visitan la ciudad de Valencia en 1599 está documentada (6) una visita a la misma. Y en 1604 se aprovecha que los Reyes están nuevamente en la ciudad para inaugurar oficialmente el Colegio-Seminario. Seguramente no es casualidad que el propio Juan de Ribera fuera virrey los dos años precedentes y, tras él, el hermano del Duque de Lerma.

- Cuarta Etapa: Terminados los elementos más importantes del edificio y a falta de revestimientos y mobiliario, baja

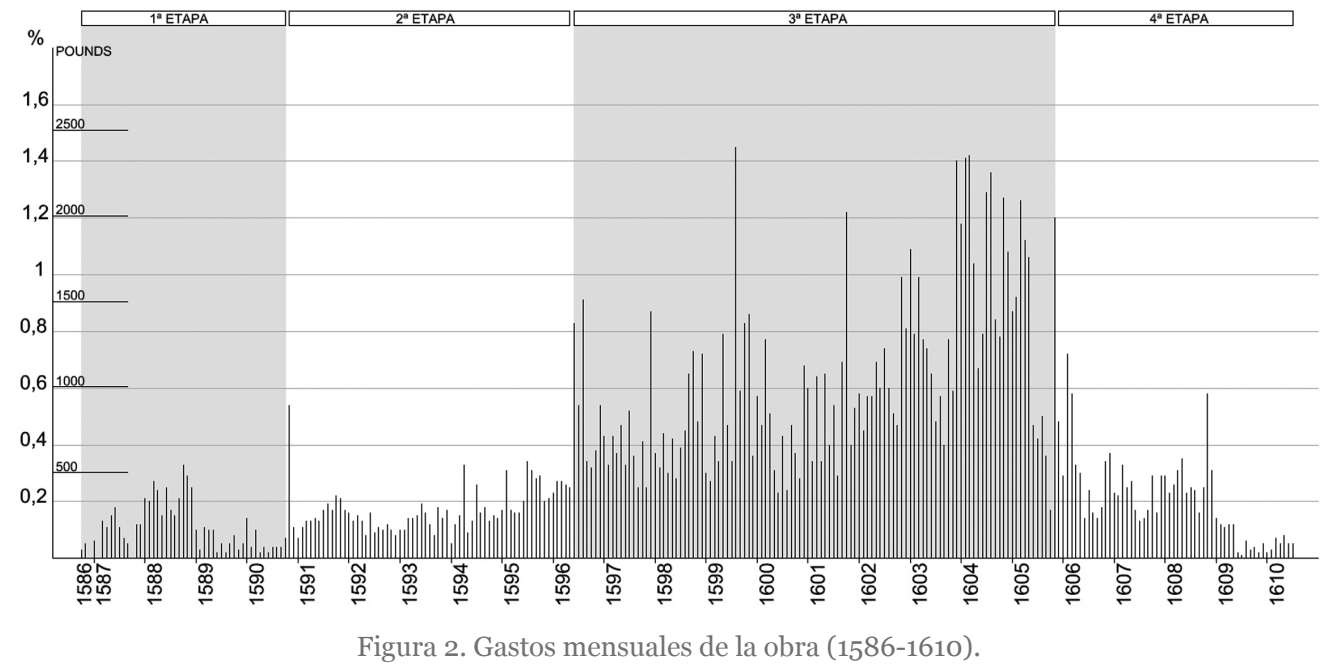

Tabla 2.

Primeros registros del Libro de Construcción del Colegio en la hoja de cálculo.

\begin{tabular}{|l|l|l|}
\hline \multicolumn{1}{|c|}{ FASES } & \multicolumn{1}{|c|}{ OBJETIVO } & \multicolumn{1}{c|}{ RESULTADOS } \\
\hline Documentación & $\begin{array}{l}\text { Identificar libros, } \\
\text { ápocas, contratos, etc. }\end{array}$ & $\begin{array}{l}\text { Libro de compras de las parcelas anteriores al edificio. } \\
\text { Libro de gastos de la construcción. } \\
\text { Contrato de la iglesia. } \\
\text { Contrato de la fachada sur. } \\
\text { Contrato del claustro. }\end{array}$ \\
\hline $\begin{array}{l}\text { Análisis } \\
\text { - Parcelas } \\
\text { - Cimentación } \\
\text { - Iglesia } \\
\text { - Fachada sur } \\
\text { - Claustro }\end{array}$ & $\begin{array}{l}\text { Analizar los } \\
\text { documentos para } \\
\text { justificar y desarrollar } \\
\text { el proceso constructivo } \\
\text { del edificio. }\end{array}$ & $\begin{array}{l}\text { Se ha establecido la relación entre la documentación y el } \\
\text { edificio construido. }\end{array}$ \\
\hline
\end{tabular}


apreciablemente el gasto medio mensual hasta el $0,36 \%$. Se inicia este período en diciembre de 1605 y concluirá en julio de 1610 .

En la Figura 3 hemos situado en color gris los materiales pertenecientes a la obra gruesa (piedra, cerámicos y conglomerantes) y en otros colores el resto para que visualmente se entienda mejor el gráfico. Los resultados constituyen el 100\% en cada uno de los años.

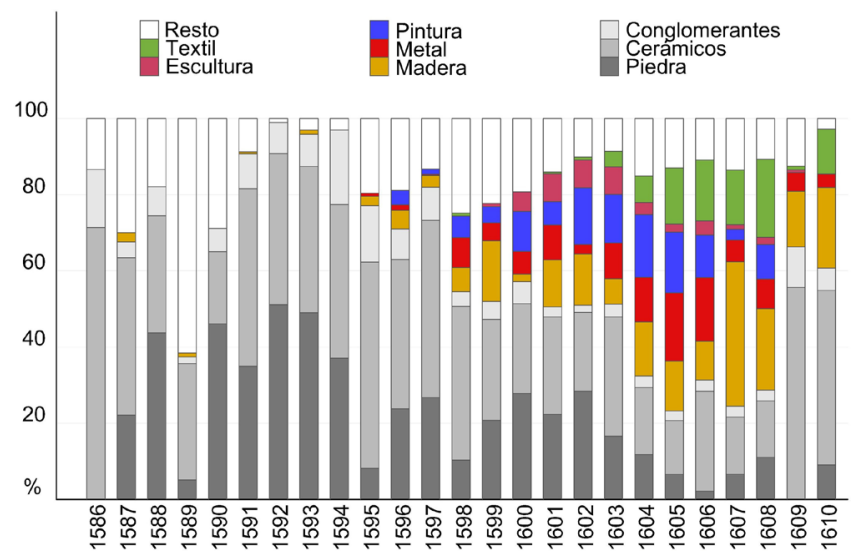

Figura 3. Gastos anuales ordenados por grupos.

\subsection{Análisis}

\subsubsection{Adquisición de los terrenos}

Desde el principio, el proceso de adquisición de casas es global en todo el ámbito del edificio, por lo que se conocía la extensión del conjunto (7). No se comenzó a comprar terrenos $\mathrm{y}$, posteriormente, se fue ampliando la parcela; este aspecto no se improvisó. En el momento en que se coloca la primera piedra, el 30 de octubre de 1586 el Patriarca Ribera aún no ha terminado de adquirir todos los solares de la manzana. Se terminó de adquirir la última parcela en el año 1601, bien avanzada la obra. Como el primer contrato formal data de 1590, hasta ahora se pensaba que la obra comenzó por la iglesia y terminó por la zona norte, de servicio, pero como veremos a continuación no ocurrió así.

\subsubsection{Cimentación del conjunto y los primeros muros}

Desde el año 1586 en que se coloca la primera piedra comenzará la obra del Colegio. Sabemos que la Iglesia, la capilla, el claustro, las celdas y la biblioteca se construyeron a partir de 1590 al estar documentado con los contratos correspondientes. Respecto a la zona de servicio del Colegio, no hemos encontrado ningún documento que acredite explícitamente su construcción ni a qué maestro de obra se le asignó. No obstante, entre 1586 y 1589 sí que hay registros de la obra que tienen que corresponder a esta zona de servicio aunque no se cite como tal. En cualquier caso, en este período de tiempo se procede a la ejecución de los cimientos de los muros perimetrales de la manzana.

Estas son algunas partidas relacionadas, según el Libro de Gastos del Colegio:

- A Pedro Bertomeu pedra-piquero: 6 reales de lo que se le debe de la piedra que asentó en las cantonadas (1587/03/9).
- A maestre Leonardo por trece carretadas piedra gruesa y asentada en la pared de la izquierda (1588/02/13).

- A maestro Leonardo por la cantonada de la cruz nueva (1588/03/31).

Los gastos relacionados con las cantonadas, según el Libro de Gastos del Colegio, son:

- Piedra de la cantonada que comenzaron Leonardo y Juan de Ambrosio a llenar todas las cantonadas que tomaron a estajo por 15 libras, se les dio la tercera parte (1588/01/9).

- Segunda paga de las cantonadas. Maestre Leonardo (1588/01/26).

- A maestro Leonardo por la cantonada de la cruz nueva (1588/o3/31).

Por lo tanto, debieron comenzar la construcción de la cimentación de la cara norte y de sus dos cantonadas (entre el primer y segundo trimestre del año 1587). La primera esquina fue a manos del maestre piedra piquero Pedro Bertomeu. Posteriormente, los maestros Leonardo y Juan de Ambrosio se encargaron de la segunda cantonada. Juan de Ambrosio continuaría con la tercera esquina, denominada la cantonada fina, que debe de hacer referencia a la esquina noroeste, que es cóncava (en febrero de 1588). En marzo y en junio de 1588 se citan las cantonadas referentes a la calle de la Cruz Nueva (Oeste) por parte de los pedra piquers Leonardo y Juan de Ambrosio nuevamente. Y, para finalizar, se nombra el último canton del Colegio (en octubre de 1588) llevado a cabo por Leonardo.

Como vemos, en cuestión de dos años se ejecutó la cimentación del perímetro del conjunto, lo que iba a ser las fachadas exteriores del mismo.

Desde el mes de abril de 1587, es decir, al mismo tiempo que se materializaba la cimentación, se contrató el alquiler de un horno en el pueblo de Moncada para la fabricación de los ladrillos, tableros y tejas que se iban a emplear en el Colegio del Patriarca. Desde este mes aparecen en el Libro de Construcción del Colegio cédulas en concepto de hornadas. Vinculados a dichas hornadas constan los registros contables de los tapiadores que estaban levantando las fachadas tanto exteriores como interiores (zona de servicio) del Colegio. Como las partes más importantes del conjunto (iglesia, capilla, zaguán y claustro) estaban en espera de formalizar el contrato para su construcción, prácticamente todas las partidas que constan entre 1586 y 1589 debieron pertenecer a los muros de las estancias de servicio.

La razón por la que esta zona de servicio se configura tan irregular en comparación con la iglesia, el claustro, la capilla, etc. puede ser debida a que la zona de servicio siempre se consideró residual y accesoria a los espacios importantes y no se cuidó la forma ni la disposición.

\subsubsection{La iglesia}

El día 16 de julio de 1590 se firma el convenio entre D. Miguel de Espinosa, rector del Colegio de Corpus Christi y el cantero Guillem del Rey, acerca de la Iglesia que dicho maestre Guillem Rey ha de hacer en dicho Colegio y Seminario. Tal y como estipula el contrato, se tenía que construir una iglesia con buenos materiales (piedra del pueblo de Godella, revisada y aceptada por el arquitecto Gaspar Gregori) 
con unas dimensiones de 170 x 74 palmos $^{2}$, siendo la nave central de 40 palmos de ancho y otros 17 palmos por cada lado del crucero.

En el Libro de Gastos del Colegio hallamos 319 gastos a Guillem del Rey a lo largo de toda la obra. El primer pago a Guillem del Rey para la Iglesia tuvo lugar el uno de marzo de 1590: A Guillem del Rey para los gastos de las obras que hacen en la iglesia del Colegio y son para la paga de este presente mes conforme al contrato (1590/03/1).

Hasta finales del año 1594 fue recibiendo pagos mensuales por valor de 100 libras a cuenta de la obra de la Iglesia. Después, en 1596, recibirá más de 800 libras en concepto de atrasos: A Guillem del Rey para poder acabar la obra de la Iglesia por 21 partidas contenidas en un borrador desde 1595/o2/21 (1596/06/2).

El alzado de la nave central (Figura 4) es de orden corintio con arcos de amplia embocadura en las capillas y radio tangente al entablamento. Por encima, aloja tribunas en cada capilla y se emplean bóvedas baídas de nervaduras en cruz para su cubrición, práctica constructiva local (8).

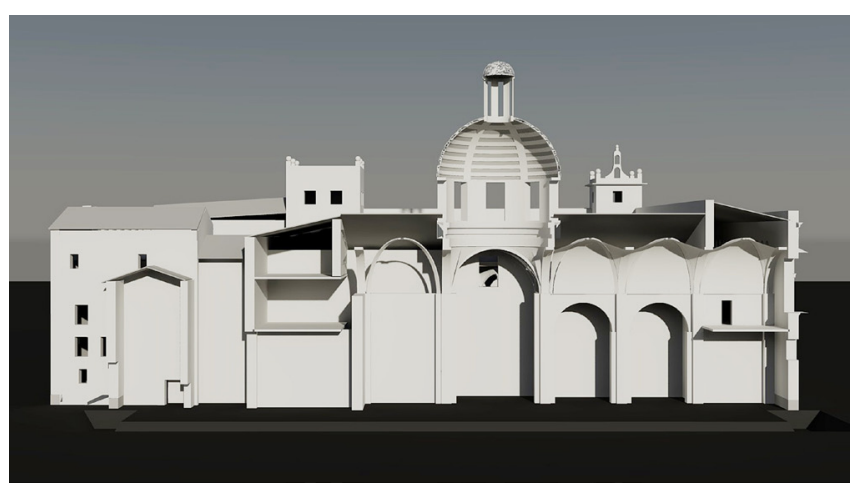

Figura 4. Sección de la iglesia del Colegio del Patriarca.

Tras este breve parón en las obras de la Iglesia en 1595 se reanudan los trabajos con el objeto de colocar el pavimento con piedra del pueblo de Ribarroja y construir las gradas. Recordemos que en diciembre de 1594 el rey Felipe III acepta el patronazgo del Colegio del Patriarca concediendo hasta 50 ooo libras para su financiación. Posiblemente este dinero se recibiera a principios de 1596 (bajo el virreinato del Duque de Lerma). Pero también es factible que, nuevamente, estuvieran pensando en modificar algún aspecto más o menos importante de la iglesia, tal y como reflejan las modificaciones que se realizaron en el crucero:

- Siete carretadas para el remiendo del crucero (1595/01/7).

- Cuatro carretadas de piedra para el otro brazo del crucero (1595/05/27).

Cabe la posibilidad de que sea en este momento en el que se reconstruye la pared de la fachada oeste que coincide con el crucero en su parte interior, pero que en el exterior sobresale del resto del plano de la fachada (Figura 5). Este hecho corroboraría la hipótesis de que en un primer momento la iglesia no debía estar situada donde hoy en día se encuentra y al modificar su ubicación hubo que reconstruir algunos muros.

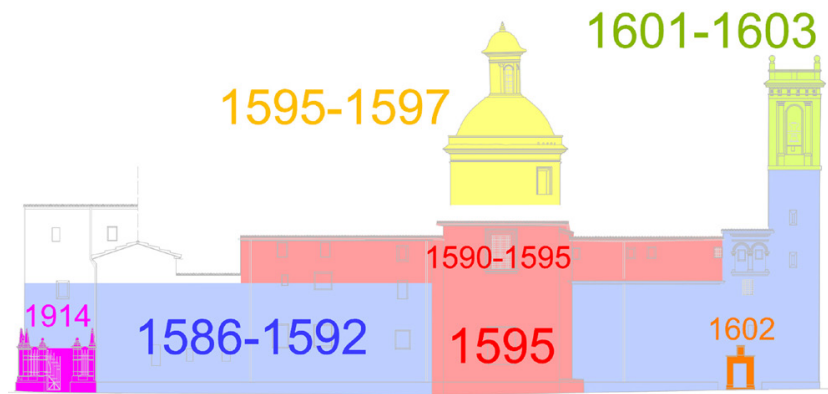

Figura 5. Cronología de construcción de la fachada oeste.

Acerca del cimborrio o tambor encontramos los siguientes gastos en el Libro de Construcción del Colegio:

- 28 piezas de plomo para cubrir el cimborrio de la iglesia (1596/06/30).

- A Guillem del Rey, una piedra y una bola para el cimborrio sobre la linterna (1596/09/15).

- Cruz del cimborrio (1596/11/2).

- A Jeronimo Guerrero y Juan de Limani por pintar de blanco y azul a 3183 tejas para el cimborrio (1596/12/31).

- Tejas para el cimborrio (1597/02/16).

La construcción de la cúpula del Colegio de Corpus Christi supone el inicio de una nueva etapa en la historia de este elemento arquitectónico. El tipo que posteriormente reproducirán otros edificios es el de media naranja, elevada sobre un tambor esbelto, apeado generalmente por los arcos torales del crucero, con extradós esférico y cubrición de teja curva vidriada (9).

Guillem del Rey pavimentará la Iglesia entre finales de 1596 y mediados de 1598, según reflejan hasta once pagos al maestro en este período. Para ello, según el contrato correspondiente, el maestre tendría que rebajar la cota del pavimento para aparejarlo correctamente: ...antes de todas cosas ha de ahondar el suelo de la iglesia y aparejarlo bien según fuere necesario para asentar todas las losas y hacer y asentar todas las gradas y vasos.

También existen varias partidas de gasto para la construcción de una serie de gradas en la Iglesia. Estas gradas son sobreelevaciones del pavimento en las capillas y en el altar, tal y como especificaban las normas del Concilio de Trento. Las gradas de la capilla de San Mauro y del altar se ejecutaron desde abril de 1604

- A Guillem del Rey por piedra de los rellanos y gradas en la salida del altar mayor de la iglesia (1601/12/15).

- A Guillem del Rey por acomodar las gradas de la capilla de San Mauro (1604/04/17).

- Bartolomé Abril y Juan Bautista Samaria también realizarán gradas, pero de mármol embutida de jaspe para el rellano de la iglesia del colegio, el rellano del altar mayor:

- A Bartolomé Abril y a Juan Bautista Samaria para cuenta de los 2000 reales que esta concertada la grada de mármol embutida que hacen para el rellano del altar mayor para el nuevo pretil (1608/04/2).

En cuanto a las dimensiones de la iglesia, cabe destacar que los 170 palmos de longitud indicados en el contrato no se adaptan correctamente al espacio real. Si comenzamos desde los pies, en el sotacoro, en realidad los laterales en su primer 
tramo no forman parte de la iglesia, pues a la izquierda tenemos la torre campanario y a la derecha el zaguán de acceso a la iglesia. En la cabecera, los 170 palmos tampoco cubren todo el espacio, y en ningún caso se alinean con la pared superior del claustro como cabría esperar. Siendo la Iglesia una pieza fundamental del conjunto, no cabe más que pensar que este es otro síntoma de que la situación original de la misma fue otra y que al intentar adaptar la planta de la iglesia al nuevo espacio tuvieron algunas dificultades.

La puerta que da acceso a la torre campanario desde el exterior ya existía, pero se remodeló en el año 1602:

- Jornales de piedra piquero para asentar la puerta pequeña de la Iglesia que sale a la calle junto al campanario $(1602 / 11 / 1)$.

Las vidrieras de la iglesia fueron colocadas por Bartolomé Matarana entre marzo y diciembre de 1598, según consta en el Libro de Gastos con cuatro partidas.

El empleo de azulejos es de gran limpieza y utilidad en zonas donde la humedad se manifiesta frecuentemente adherida a la parta baja de las paredes y destruye lo que se pretende fijar en ella (10). Hay que hacer notar que antes del chapado se procedió al cortado de los azulejos, desde el 9 de diciembre de 1596 hasta el 14 de junio de 1603. Por último, la iglesia se chapó con azulejos. Los primeros gastos al respecto son más bien tempranos:

- Cortar azulejos a Antonio Corbaran Albanez (1596/12/9).

- Rajoletas que hace para chapar el colegio (1597/09/22).

- Cortar la piedra de la iglesia para chapar de azulejos (1597/12/20).

\subsubsection{La fachada sur}

De gran sencillez y austeridad en general, aunque en la parte alta muestra una galería de arquillos dóricos con acabado de ladrillo aplantillado y cortado con un entablamento de triglifos y metopas.

Pensamos que la fachada sur no se construyó de una sola vez (Figura 6), sino que en un primer momento se encontraba levantada hasta una cierta altura y Miguel Rodrigo y Antonio Marona impusieron la cota actual.

Si analizamos el contrato de 1593 para la construcción de la fábrica del Colegio recayente a la calle de la Nave podemos extraer algunas conclusiones interesantes respecto a la posibilidad de un muro preexistente. En este contrato, el rector D. Miguel de Espinosa acuerda las condiciones de ejecución de la obra con los maestros Rodrigo y Marona, llamados canteros o architectos. En el primer apartado ya se impone la necesidad de derribar la parte alta de la pared que recae a la calle de la nave y la puerta principal, de tal forma que haya que volver a tapiar lo eliminado para construir la primera cubierta (...) se hayan de encajar los revoltones en la tapia que se hará nue$v a$ (entendemos la cubierta del primer espacio, el primer forjado) de tal forma que el pavimento se enrase con el del coro. En otro ítem se define el espesor que ha de tener el muro: las paredes se hayan de hacer del mismo espesor que hoy están.

Es decir, anterior al año 1593 ya existía parte de la fachada principal, que se tiene que derribar y volver a construir para adaptarse a la nueva cota impuesta por el coro que, por tan- to, fue construido a posteriori que la fachada. Además, en el primer ítem se nombra la puerta principal, por lo que ya estaba materializada una puerta. Como se indica, el grosor que debe tener la pared es el del muro que ya está construido en ese momento. Pensamos que ya existiría un muro construido pero de poca altura, lo necesario para construir una puerta y poder techar el espacio de forma provisional, pero en ningún caso tendría la altura actual.

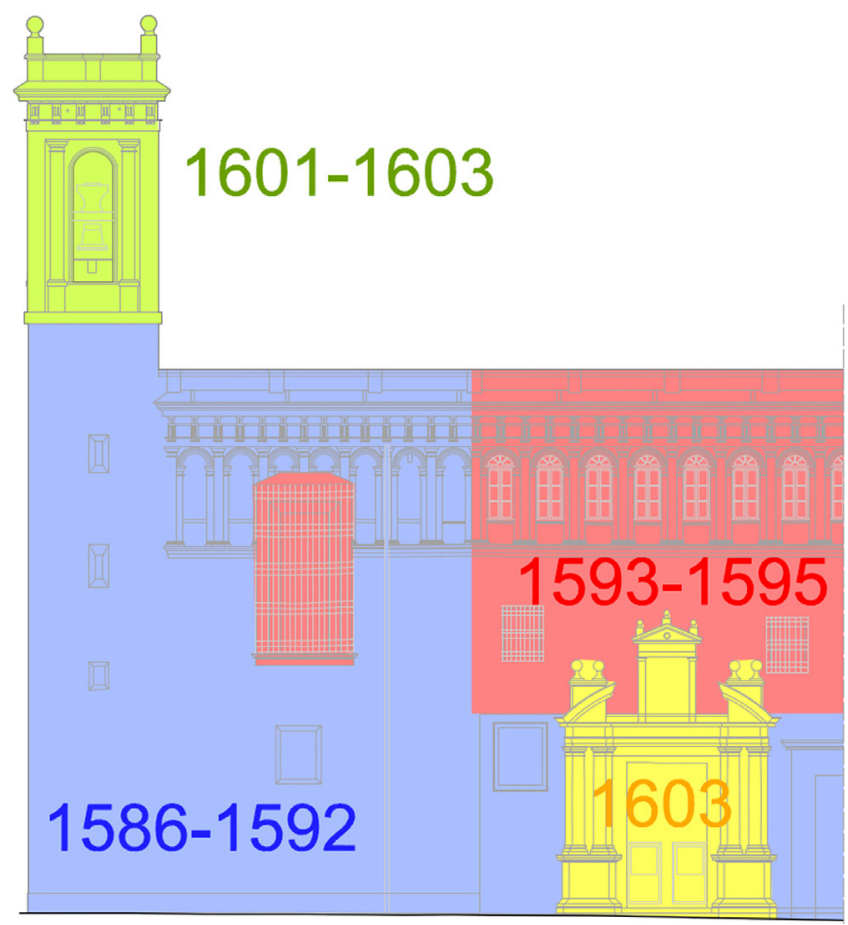

Figura 6. Cronología de construcción de la fachada sur.

El tramo entre el cantón de la torre-campanario y la puerta principal debía estar completamente terminado hasta su altura actual, seguramente en 1589 . Al contratarse la iglesia con Guillem del Rey en 1590 se introdujeron algunas modificaciones como es el caso del coro. A esta incorporación se le sumaron nuevos cambios; a saber: el primer tramo de arquillos en la calle de la Nave se ciega y se abre un nuevo hueco rectangular de grandes dimensiones que iluminará el coro. Como se ha comentado, también se tendrá que derribar parte de la pared ya construida y se tendrá que volver a levantar para ajustarse a la nueva cota impuesta por el coro.

También se indica que la paret de la tapia sea de la misma manera y la que es de paredado que sea del mismo orden. Este apartado obliga a los maestros a ejecutar el nuevo tramo del muro de la misma manera, dimensiones y forma que el que ya existía y diferencia la pared hecha de tapial de la realizada en ladrillo visto con arquillos (que sea del mismo orden). Por lo que ya no queda ninguna duda de que el primer tramo de la fachada sur ya estaba ejecutada en el momento del contrato con Marona y Rodrigo.

Lo que no es menos cierto es que se aprecia una discontinuidad en la traba entre la fábrica de la torre y la inmediata de los arquillos de tal forma que parece que la torre se construiría en primer lugar y luego el primer tramo de arquillos.

Asimismo, viendo el alzado general de la fachada sur se remarca una gran grieta que se inicia en el antepecho de cubier- 
ta y desciende hasta el arranque el muro. En detalle podemos apreciar que los triglifos de la parte izquierda y los de la derecha no son exactamente iguales. Además, en el antepecho de cubierta, la parte de la derecha tiene tendeles más gruesos.

En el ítem XXV se obliga a los maestros a reutilizar la tierra y medias de la pared derribada:

«...acabado el cuarto o antes hayan de derribar la pared de la calle y meter la tierra y medias dentro en el lugar que se les señalare o gastarlo en la misma obra y la paga de esto haya de ser en tres tercias como se acostumbra en los estajos...»

En el Libro de Gastos del Colegio encontramos entre los años 1593 y 1595 una gran producción en el horno que trabaja para la obra. Así, de las partidas que tenemos detalladas, podemos extraer que se fabricaron más de 342300 ladrillos gordos, 18300 tableros, 34900 tejas, 30250 atobas y más de 280 libras en leña. Veamos algunas de esas partidas:

- 1300 ladrillos grandes, 2150 átobas de madera para los portales de junto a la escalera, 1000 ladrillos gordos (1593/o7/19).

- 13000 ladrillos gruesas y 1000 tejas chicas y 1000 tableros (1594/09/21).

- 10000 ladrillos gordos y 4300 ladrillos delgados y 300 abonas (atobas) con los gastos sin la leña (1595/07/2).

En el contrato con Rodrigo y Marona también se indica que hay que hacer la tapierra necessaria hasta llegar a lo alto de la segunda cubierta dexando sus ligadas para la demas obra. Como ya se ha comentado, la ejecución de los muros que no eran de ladrillo visto se realizaban mediante la técnica del tapial.

En el concierto se fija en el ítem XXI:

«...que dichos compradores arrendadores hayan de hacer a su costa la costra y mortero primo y grueso para dicha obra y asimismo hayan de adobar la tierra para hacer la tapierra como se requiere para que sea de provecho y como se requiere adobar y cavar la tierra que hubiere menester de la que está dentro del ámbito.»

Por todo, el Patriarca se comprometía a pagarles 850 libras. No obstante, y aunque no está registrado en el Libro de Gastos, Boronat (11) comenta que se tasó la fábrica en 921 libras aunque el Patriarca finalmente gratificó a los maestros con 1750 libras.

\subsubsection{El claustro}

El 26 de noviembre de 1599 Guillem del Rey firma el contrato para ejecutar el claustro del Colegio de Corpus Christi según un diseño de Miguel de Espinosa que tendría que respetar:

Hacer el claustro bajo y alto del Colegio y dejarlo en toda perfección remendadas columnas, vasas y capiteles y hechas las que faltan de mármol, hacer una escalera y pretil del coro y losa para la sepultura en concierto con el maestro Guillem del Rey por 6000 libras en Valencia, de Octubre de 1599, acto recibido por Jayme Cristoval Ferrer. En Valencia, a 4 de Noviembre de 1599 para principio de paga a Maestre Guillem del Rey, 600 libras.

La formalización definitiva del claustro está ligada a las columnas de mármol blanco de Génova que el Patriarca compró a la Duquesa de Pastrana en 1599, aunque en 1596 consta que hizo venta, de palabra (...) de todas las columnas con sus basas y capiteles de mármol que se hallaren entonces así en la Ciudad de Alicante como en la Ciudad de Cartagena. No obstante, en junio de 1595 el maestre Alonso fue a ver las columnas. En 1597 hay pagos por el porte de algunas columnas desde Alicante, en barco:

- A Miguel Salerno patrón de la barca por los monolitos de 8 basas y 8 capiteles de las columnas de mármol, 55 quintales (1597/01/23).

- El Patriarca en marzo pasado envió su maestro Alonso a Cartagena para que hiciese embarcar las columnas que allí están comprados de Don Carlos Juan que las vendió con poder de la madre del duque de Francevilla (1597/12/31).

Tras la compra, el almacenaje y el transporte hasta Valencia, en agosto de 1599 se acaban de evaluar los daños para en el mes de noviembre Guillem del Rey comenzar las obras:

- Se acavaron de tascar los daños y menoscavos de las columnas, basas y capiteles de los marmoles que vendio Don Carlos Juan que estavan en Alicante y Cartagena los cuales iran de los hercaderos del Duque de Francia Vila fueron concertados a 33 libras columnas, vasa y capitel descubiertos de tierra en los lugares dichos, estan ya contiunados los nolito (1599/08/23).

El grueso de la obra se ejecutó entre 1599 y 1601 tal y como estipulaba el contrato, aunque entre 1602 y 1603 se construyeron las bóvedas y también la balaustrada del piso superior. Posteriormente hay pagos en concepto del claustro de arriba. En 1603 constan tres pagos para realizar el pavimento del claustro del colegio y otros tres para la realización de la fuente. A comienzos de 1604 se empieza a chapar con azulejos.

El claustro tiene una configuración rectangular (Figura 7) de 8 vanos de largo por 5 de ancho, la cual se acerca a la proporción áurea. En el contrato de ejecución del claustro de 1599 parece que se tienen dudas acerca del diseño del mismo, pues constantemente se hace referencia a que puede ser modificada la traza:

- Ittem que si en el discurso de la obra del dicho claustro parecera al dicho Retor muda mejorar o variar una o mas cosas de las contenidas en la traça y capitulacion de aquella lo pueda hazer como no sea despues de bien labradas o asentadas conforme a la traça y capitulacion de aquella y si en el discurso de la dicha obra se descubriera una o mas cosas necesarias para la utilidad o policia de la dicha obra y aquellas por discuydo vel alias se habran dexado de poner en la traza y capitulacion de la dicha obra sea tenido y obligado el dicho Guillem de Rey de hazer aquellas a mera voluntat del dicho Retor sin que pueda pedir ni haver mejora o refaicion alguna por quanto el dicho Guillem del Rey se ha ofrecido deixar acabado en suma perfection el dicho claustro y las demas cosas questan a su cargo conforme a este auto de la capitulacion por el precio que abaixo se dira y se declara.

En el contrato se le obliga a Guillem del Rey a realizar 26 arcos y 22 pedestales con las 4 esquinas, lo que nos hace pensar que ya manejaban esa dimensión de $8 \times 5$ vanos, pero no estaban convencidos o tenían miedo de que a la hora de construirlo faltaran o sobraran columnas. Tiene, además, dos 
alturas y se decidió emplear la superposición de órdenes de tal manera que el dórico se sitúa en la planta baja y el jónico en la superior. Para el orden dórico se requerían 30 de las 48 columnas grandes que se compraron; para el orden jónico se necesitaban también 30 de las 37 columnas pequeñas adquiridas. Se le obligó al maestre a comenzar por las cuatro esquinas para, a continuación, proceder con los arcos y columnas.

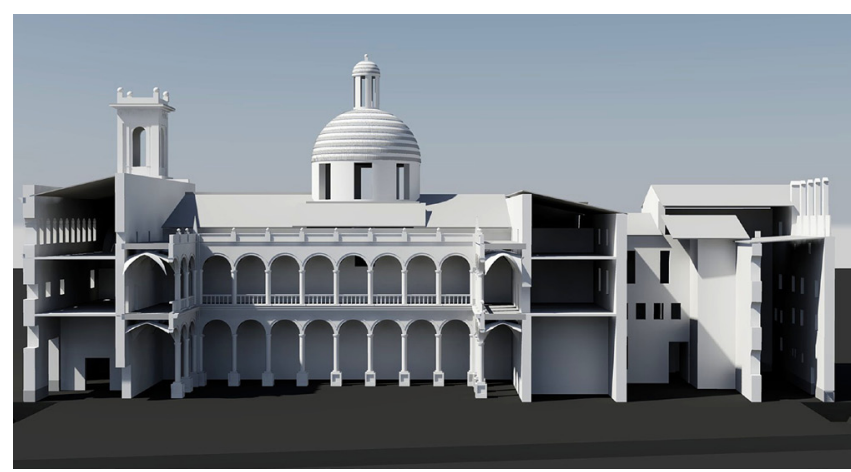

Figura 7. Sección norte-sur del Colegio con el claustro en posición intermedia.

En el diseño del alzado, se fija el intercolumnio con la dimensión de las columnas jónicas, de tal forma que en la planta jónica una columna más el arco de medio punto es igual a 1,5 veces el intercolumnio. En la planta dórica, la altura total es 2 veces el intercolumnio, cubriéndose la altura restante con los pedestales (12).

\section{RESULTADOS}

En la Tabla 3 se muestra el resultado de la investigación, es decir, las diferentes fases del proceso de construcción del Colegio de Corpus Christi, así como las incongruencias detectadas.

Del análisis de la documentación comentada en este artículo hemos elaborado un modelo tridimensional del ColegioSeminario de Corpus Christi reflejando en la Figura 8 un resumen de la evolución del proceso constructivo del Colegio. Mientras aún no se había terminado de comprar las parcelas de la manzana del Colegio, en 1586 comenzó la construcción del edificio desde la esquina noreste. En dirección hacia el Oeste y luego hacia el sur (contraria a las agujas del reloj) se ejecutó la cimentación de los muros perimetrales de la manzana. Hasta 1589 se construiría también parte de estos muros. En 1590 está documentado el primer contrato que se conserva con el maestro Guillem del Rey para la construcción de la iglesia. Entre 1593 y 1595 los maestros Miguel Rodrigo y Antonio Marona construirán la parte superior de las fachadas sur y este. En este mismo año de 1595 están documentadas modificaciones en el crucero de la iglesia que responden al saliente de la fachada oeste. Entre 1595 y 1597 se construyó el tambor y la cúpula de la iglesia. Entre 1599 y 1604 se ejecutarán las distintas fases del claustro (columnas, arcos, bóvedas, azulejos...). Finalmente, en el último tercio del proceso disminuyeron los gastos de la obra gruesa y se incrementaron los gastos de los acabados (mobiliario, relicarios, textil, pinturas...). Entre 1602 y 1605 finalizó el último tramo de la torre campanario. Tras la inauguración oficial del edificio por parte del Rey Felipe III en 1604 decae el gasto hasta 1610 en que la configuración general del edificio adquiere la forma con que ha llegado hasta nuestros días.

\section{DISCUSIÓN}

Si desarrollamos las observaciones reflejadas en la Tabla 3, queda patente que algunas cuestiones no quedan clarificadas. Observamos en primer lugar que entre 1586 y 1588 hay una actividad constructora importante (con gastos mensuales que llegan en algunos casos a sobrepasar las 500 libras), pero desde noviembre de 1588 desciende bruscamente el gasto hasta noviembre de 1590 en que se formaliza el primer contrato con Guillem del Rey para la Iglesia. Esto se puede interpretar como un período de espera para reflexionar o modificar el proyecto, seguramente influidos por la publicación de Las Estampas de El Escorial.

En 1589 Herrera termina el Escorial y publica una serie de doce plantas, alzados y secciones del edificio. También aquél año Herrera publicó el Sumario y Breve Declaración de los diseños y estampas de la Fabrica de San Lorenzo el Real del Escorial. Dicho Sumario nombra cada estampa y la explica con letras y símbolos de referencia (13).

Si observamos el Colegio de Corpus Christi nos llama la atención algunos acabados compositivos y morfológicos porque resaltan sobre el contorno, debidos en general a una constante improvisación del proyecto de ejecución al no estar perfectamente definida la solución final y a que durante la misma construcción del edificio se tomaron decisiones que modificaban lo construido hasta ese momento. En este artículo se propone una hipótesis compositiva del conjunto según la cual las partes más importantes del edificio podrían haberse situado en otro lugar y durante la obra haberse modificado dando lugar a ciertas incongruencias en la planta, en las fábricas o en los huecos del Colegio.

En la época era habitual realizar un modelo, por ejemplo en madera o unas trazas generales y otras para cada parte que se iba contratando (en el contrato para una parte del edifi-

Tabla 3.

Resumen de los resultados de la metodología aplicada.

\begin{tabular}{|c|c|c|}
\hline ELEMENTO & CRONOLOGÍA & OBSERVACIONES \\
\hline Parcelas anteriores & $1580-1601$ & Se adquieren parcelas incluso después de comenzar la obra. \\
\hline Cimentación & $1586-1589$ & Siguiendo la secuencia de adquisición de las parcelas. \\
\hline $\begin{array}{l}\text { Iglesia } \\
\text { - Modificación crucero } \\
\text { - Cúpula-cimborrio } \\
\text { - Torre-campanario }\end{array}$ & $\begin{array}{l}1590-1598 \\
1595 \\
1595-1596 \\
1601-1603\end{array}$ & $\begin{array}{l}\text { Antes del inicio hay una parada para estudiar las Estampas } \\
\text { de El Escorial, publicadas en } 1589 . \\
\text { Se modifica el muro del crucero antes de la construcción } \\
\text { del cimborrio y la cúpula. } \\
\text { Se modifica la cota del coro. }\end{array}$ \\
\hline Fachada sur & $1593-1595$ & $\begin{array}{l}\text { El contrato evidencia que se han producido modificaciones } \\
\text { respecto del diseño inicial. }\end{array}$ \\
\hline
\end{tabular}



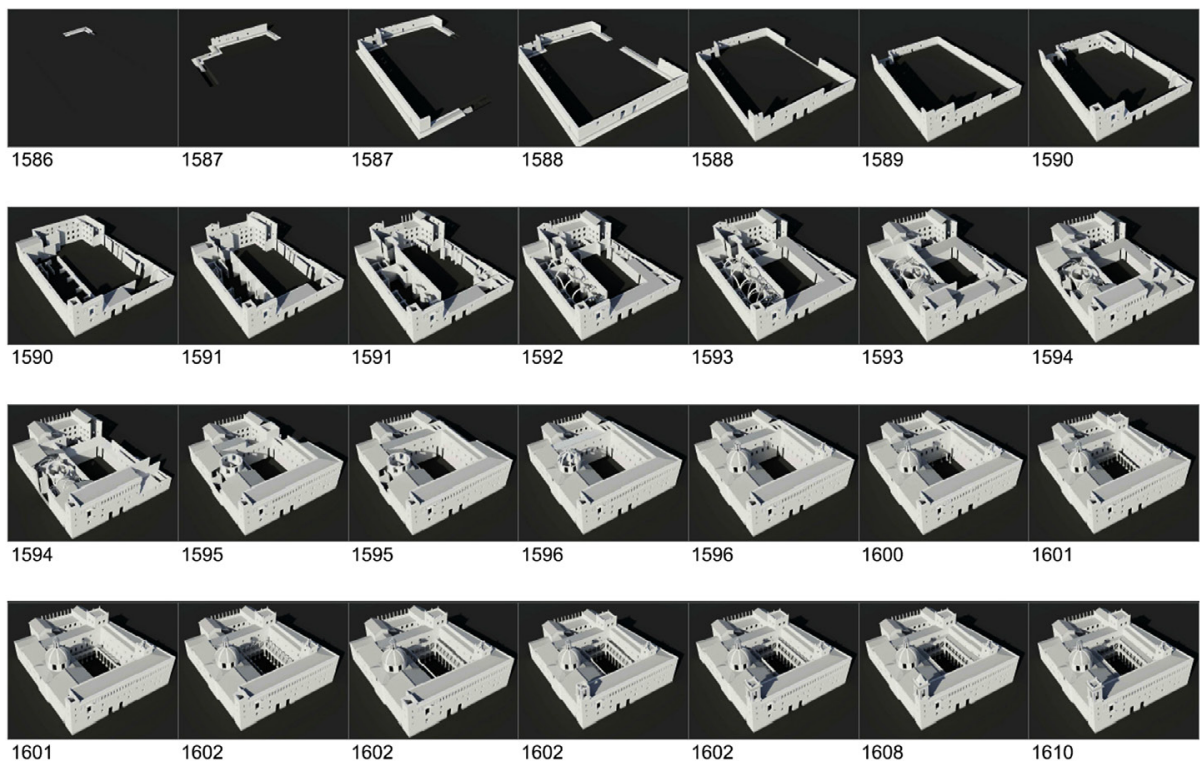

Figura 8. Proceso constructivo mediante un modelo tridimensional del edificio.

cio, se especificaban unas condiciones generales de la obra, derechos y obligaciones del contratista/ejecutor y de la propiedad. Además se daban unas trazas acompañadas de capitulaciones que, seguramente, se emplearían en la propia obra, motivo por el cual no han llegado hasta nuestros días.), pero las cicatrices que observamos hoy en el Colegio del Patriarca no denotan solamente improvisación y modificaciones sobre el transcurso de la obra, sino más bien un cambio importante en las trazas, seguramente la modificación de la posición y dimensión de la iglesia. Tal y como la vemos en la planta actual no encajan bien las dimensiones que se citan en el contrato correspondiente, además de los arcos cegados en la fachada sur para posteriormente abrir el hueco de la ventana del coro. También se modificaron a posteriori los muros de cerramiento en el crucero.

No negamos la posibilidad de que desde el principio las trazas previeran la situación de la iglesia en el mismo lugar en el que hoy se encuentra, pero nos hemos planteado si existe la posibilidad de organizar los elementos del conjunto de otra forma, y tan solo existe una, la de la Figura 9.
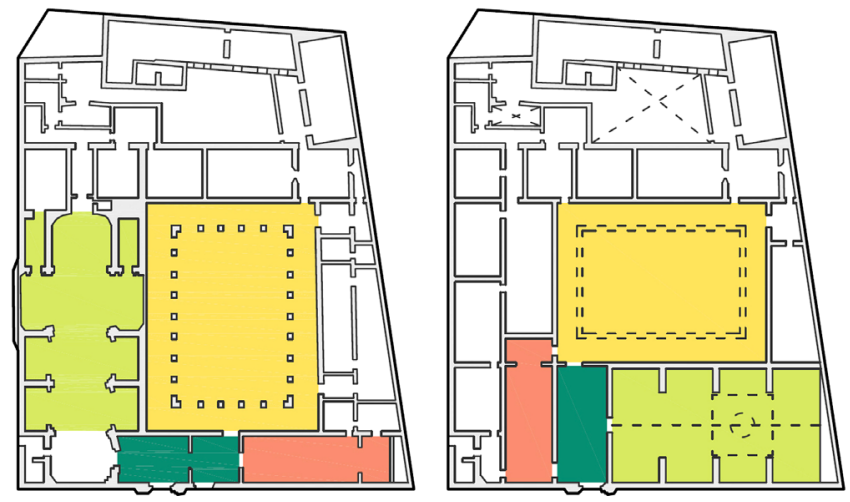

Figura 9. Hipótesis de trazas previas a la configuración actual.

Es factible pensar que durante el año de 1589 ya se habían construido los muros significativos de la zona de servicio y del perímetro del conjunto, faltando todavía los elementos más importantes: la iglesia, el claustro, la capilla y el zaguán que los articula. Si en ese momento se decide cambiar las trazas no se presentaban grandes inconvenientes porque esta zona está en su mayor parte por construir.

Es más, al construir la iglesia tal y como la conocemos, con el coro elevado a los pies de la iglesia, en 1593 se iniciarán los trabajos de la fachada sur advirtiendo que hay que derribar parte de la pared, modificar la cota del forjado para alinearlo a la del coro.

En la Figura 9 podemos comparar la posición y el tamaño de los espacios más representativos en su situación actual y en la hipótesis que planteamos. A saber: el claustro, la iglesia, el zaguán y la capilla. De estos, solo el claustro pudo tener una dimensión menor a la actual; el resto son iguales.

En el contrato de la fachada Sur y Este, de 1593, se hace referencia a una única puerta, la puerta principal: ...la pared que cae a la parte del estudio y a la puerta principal.... Además, la puerta que subdivide el zaguán es posterior (realizada en 1596), tal y como consta en el contrato con Guillem del Rey para la terminación de la iglesia del Colegio:

E primeramente ha sido pautado, avenido y concertado entre las dichas partes que el dicho maestre Guillem de rey ha de hacer una portalada de piedra muy buena de la pedrera de Godella de buen grano sin mollerones del alto y ancho de la misma hechura y obra con sus armas y ornato como esta labrada la puerta principal de la iglesia del dicho collegio y sentalla frontero de la misma puerta con la misma obra sin faltar cosa de lo que la asentada tiene con sus armas $y$ ornato y que se hagan los andamios.

Confirmado por una partida encontrada en el Libro de Gastos:

- A Guillem del Rey 2000 reales castellanos para portada que ha de hacer en el Colegio en la puerta que esta frontera de la puerta de la Iglesia del Colegio y de solar la Iglesia y gradas (1596/07/28).

En la disposición alternativa, los elementos importantes: campanario, capilla, zaguán e iglesia dan a la fachada prin- 
cipal, la Sur, y es el claustro el que articularía el espacio con la zona del Colegio y de servicio. Lo que indicaría que los elementos principales se situarían junto a la Universidad y a la plaza y los espacios servidos se colocarían en la parte posterior. En la disposición actual de la planta, estos elementos están distribuidos entre las fachadas sur y oeste.

\section{CONCLUSIÓN}

Tener la posibilidad de estudiar un edificio como el Colegio de Corpus Christi, con más de 400 años de historia y prácticamente en su estado original, es un aliciente en sí mismo. Pero además, es una de las pocas instituciones que conserva en su archivo valiosísimos documentos, algunos de los cuales hemos podido analizar y extraer información relevante para nuestra investigación. El presente trabajo se ha centrado en el estudio y análisis del conjunto edificado desde un punto de vista arquitectónico y constructivo.

La arquitectura de la Contrarreforma estuvo influenciada por la obra de Carlos Borromeo Instructiones Fabricae et Supellectilis Ecclesiasticae, publicada en 1577, seis años antes de la fundación del Colegio del Corpus Christi y nueve antes del comienzo de las obras.

Hemos realizado un tratamiento informático de los datos que se encuentran en el Libro de Construcción del Colegio, facilitando la elaboración de un estudio gráfico de los gastos, incluyendo los materiales de construcción empleados, autores, coste de la obra, etc. La información que se recoge del libro son las distintas partidas de obra, fechadas y agrupadas por meses y años. Hemos realizado un vaciado de la información contenida en el libro y la hemos informatizado de tal forma que nos ha permitido ordenar cronológicamente todas las partidas, sumar las cantidades y filtrar resultados con el objetivo de conseguir resultados escritos o gráficos que nos han ayudado en el desarrollo de este trabajo.

Podemos resaltar la Figura 3 en que se muestran, con periodicidad mensual, todos los gastos generados en la obra, de tal forma que intuitivamente se puede entender cómo evolucionó la magnitud de la empresa llevada a cabo por el Patriarca. De una parte, conocemos el intervalo de tiempo en el que se construyeron las distintas piezas del conjunto, como por ejemplo: la iglesia, la fachada sur, el claustro, el campanario, etc. De otra parte, sabemos cuál fue el gasto mensual, por lo que se puede establecer una relación entre esas piezas y el volumen de gasto relacionado.

Queda patente que entre los años 1586 y 1588 hay una actividad constructora importante (con gastos mensuales que llegan en algunos casos a sobrepasar las 500 libras valencianas), pero desde noviembre de 1588 desciende bruscamente el gasto hasta noviembre de 1590 en que se formaliza el primer contrato con Guillem del Rey para la Iglesia. Esto se puede interpretar como un período de espera para reflexionar o modificar el proyecto, seguramente influidos por la publicación de Las Estampas de El Escorial.

El Libro de los Gastos de la Construcción del edificio nos ha permitido establecer también la relación entre los distintos artistas o maestros, las obras que realizaron y el período histórico en que trabajaron para el Patriarca Ribera.

Este artículo aporta una explicación coherente para algunas de las incongruencias que la construcción del edificio todavía planteaba, como el resalto del crucero en la fachada oeste, la ventana del coro y su fábrica o la construcción de las distintas partes del edificio. Para ello, se ha formulado una hipótesis de trazas previas que se debieron rectificar y, por tanto, modificaron algunos aspectos importantes de la construcción del edificio. Las situamos temporalmente antes de la adquisición de los solares del ámbito del Colegio, en 1580. Consideramos al maestro Gaspar Gregori como posible autor de estas trazas, ya que en 1576 trabajaba para el Patriarca en la iglesia de Cocentaina. Se ha investigado qué sucedió entre el inicio de las obras a finales del año 1586 y el momento en que se formalizó el contrato de la Iglesia en 1590. En este sentido, es muy relevante el proceso constructivo que hemos podido documentar. Se ha atendido a la financiación de la obra, la adquisición de los terrenos, la cimentación del conjunto, los primeros muros, la iglesia, la fachada sur, las pinturas, las escaleras, el claustro, la torre-campanario y a los materiales.

\section{AGRADECIMIENTOS}

Agradecemos la colaboración de D. Miguel Navarro Sorní, el Director del Seminario-Colegio de Corpus Christi en Valencia, y del profesor D. Pablo Pérez, quien nos facilitó el acceso a los archivos del edificio.

\section{REFERENCIAS}

(1) Llopis-Verdú, J. (2002). Gaspar Gregori y la introducción de la metodología proyectual renacentista en Valencia. Revista EGA, (7): 48-59.

(2) Aliaga, I. (1631). Advertencias para los edificios y fabricas de los Tenplos. Valencia.

(3) Lerma, C., Mas, A., Blasco, V. (2013). Analysis Procedure of a Previous Planning Organization - The Area of the Seminary-School of Corpus Christi in Valencia, Spain. International Journal of Architectural Heritage, 7(2): 135-152.

(4) Anónimo. (1892). Libro de los Gastos de la Construcción del Colegio del Patriarca. Copia del original. Archivo del Colegio del Patriarca, Valencia.

(5) Yastikli, N. (2007). Documentation of cultural heritage using digital photogrammetry and laser scanning. Journal of Cultural Heritage, 8(4): 423-427, doi: http://dx.doi.org/10.1016/j.culher.2007.06.003.

(6) Cabrera-de Córdoba, L. (1857). Relaciones de las cosas sucedidas en la Corte de España desde 1599 a 1614. p. 20, Madrid. Imprenta de J. Martin Alegria.

(7) Anónimo. (1600). Libro de Compras de casas encorporadas en el Collegio y Seminario fundado por el Illustrísimo señor Don Juan de Ribera, Patriarcha y Arçobispo de Valencia. Archivo del Colegio del Patriarca, Valencia, ca.

(8) Benito-Doménech, F. (1991). Real Colegio y Museo del Patriarca. p. 30, Valencia. Ed. Consell Valencià de Cultura.

(9) Soler-Verdú, R. (1996). Cúpulas en la arquitectura valenciana de los siglos XVI a XVIII. Actas del Primer Congreso Nacional de Historia de la Construcción. p. 491-498, Madrid. Ed. Ministerio de Fomento y CEDEX. 
(10) Vizcaíno-Martí, Ma E. (1999). Azulejería Barroca Valenciana. Valencia. Ed. Federico Domenech S.A.

(11) Boronat i Barrachina, P. (1904). El B. Juan de Ribera y el R. Colegio de Corpus Christi: estudio histórico. p. 278, Valencia. Impr. de Francisco Vives i Mora.

(12) Llopis-Verdú, J. (2007). El claustro del colegio de Corpus Christi de Valencia. Análisis formal y compositivo. Archivo Español de Arte, 80(317): 45-65.

(13) Wilkinson-Zarner, C. (1996). Juan de Herrera: Arquitecto de Felipe II. Madrid. Ediciones Akal. 